\title{
Trend Improving Soccer Professional Referees Performance in West Java Using Psychological Skill Training and Physical Fitness
}

\author{
Deni Mudian ${ }^{1, *}$, Moch Asmawi ${ }^{1}$, Taufik Rihatno ${ }^{1}$, Muhsana El Cintami Lanos ${ }^{2}$, \\ Veny Elisyah $^{1}$, Tri Aji \\ ${ }^{1}$ Sport Education, Program Pasca Sarjana, Universitas Negeri Jakarta, Indonesia \\ ${ }^{2}$ Sport Education, Universitas PGRI Palembang, Indonesia \\ ${ }^{3}$ Sport Education, Universitas Negeri Semarang, Indonesia
}

Received March 7, 2021; Revised May 6, 2021; Accepted May 23, 2021

\section{Cite This Paper in the following Citation Styles}

(a): [1] Deni Mudian, Moch Asmawi, Taufik Rihatno, Muhsana El Cintami Lanos, Veny Elisyah, Tri Aji, "Trend Improving Soccer Professional Referees Performance in West Java Using Psychological Skill Training and Physical Fitness," International Journal of Human Movement and Sports Sciences, Vol. 9, No. 3, pp. 595 - 601, 2021. DOI: $10.13189 /$ saj.2021.090328.

(b): Deni Mudian, Moch Asmawi, Taufik Rihatno, Muhsana El Cintami Lanos, Veny Elisyah, Tri Aji (2021). Trend Improving Soccer Professional Referees Performance in West Java Using Psychological Skill Training and Physical Fitness. International Journal of Human Movement and Sports Sciences, 9(3), 595 - 601. DOI: 10.13189/saj.2021.090328.

Copyright $\bigcirc 2021$ by authors, all rights reserved. Authors agree that this article remains permanently open access under the terms of the Creative Commons Attribution License 4.0 International License

\begin{abstract}
The referee has an important role in football matches. The referee determines the level of fairness in the match so they must be mentally and physically fit. The purpose of this study was to examine the application of psychological skills training and the level of physical fitness to the performance of the referee. Psychological skill exercises used are relaxation, imagery, and relaxation-imagery combination that exist in conditions of high and low physical fitness. This research is quantitative with a quasi-experimental method. The research sample consisted of 48 people who were taken using purposive sampling based on the criteria that the referee had a provincial level referee license (Code $\mathrm{C} 2$ ) and has led a provincial level competition. Data collection techniques are through pre-test, post-test and treatment during the study. The data analysis technique used two-way ANOVA analysis followed by the Tukey test. The findings showed that psychological skill training, both relaxation, imagery, or a combination of imagery-relaxation and physical fitness, had a positive effect on the performance of the referee in leading the match. These results have implications for the concept of psychological training for football referees in West Java, especially during the
\end{abstract}

Covid-19 pandemic, who had limited access to training in the field. However, this psychological skill training makes it easier to train the referee mentally.

Keywords Football, Psychological Skills, Physical Fitness, Referee, Training

\section{Introduction}

The referee has the authority to regulate the match. In addition, the referee can also make decisions about the actions of players who commit violations. Every decision by the referee has implications for the outcome of the match.[1][2] Also, the actions of the referees on the pitch such as making decisions show their performance.[3] It means that every action of the referee in making decisions about the course of the match leads to professional performance. Often, the decision-making process is also based on rules or game management. So, the referee uses subjective limits also in match management.[4] The referee on the field also usually determines the 
decision-making context according to the central referee.[5] During the process of determining decisions regarding various events that occur in the match by the referee, it is not only influenced by the referee's management in managing the match. Also, decision making by the referee involves the use of context.[6]

However, the audience, team officials and players often feel dissatisfied with the referee's decision which has an impact on the referee's psychology.[7] They must have a stable emotional level and calmness in the face of protests from players, and team officials or crown noise from the audience,[8] so that there will be no fights that result in harassment of the referee or the match is stopped. As happened in France and the Netherlands, referees often feel that they have been subjected to verbal or physical abuse during football matches.[9] It is an obstacle in football matched that must be faced by referees.[10]

Referees who are able to face various obstacles during the match show how good and quality the referee's performance is in leading the match. Many factors affect the quality of the referee's performance in the match. The referee must prepare his physical fitness, knowledge or mental psychology as well as personality in leading, level of self-confidence, or emotional balance.[11]

Therefore, referees in soccer matches must always improve their professional performance, as has been done by soccer referees in West Java. They do various physical activities to support their physical fitness level and train the balance of psychological skills. This is due to the analysis of the performance of referees in West Java in leading a football match shows that emotional problems often occur as a result of the treatment of players, officials or audiences who often harass the referee, so that the referee is often out of control of his emotions and avenges their actions which should not be done by the referee. Efforts to overcome this problem require the application of psychological skills training methods so that the referee can control emotions and other mental problems. According to Valey,[12] there are four psychological skills training techniques, namely Imagery, goal-setting, thought management and physical relaxation/arousal regulation. Efforts to overcome this problem require the application of psychological skills training methods so that the referee can control emotions and other mental problems and environment condition.[13]

Referee behaviour is often influenced by the mental moderation effect between self-efficacy beliefs and perceptions of adaptation in the team to become a professional referee.[14] Therefore, a special training program must be given to the referees so that they can deal with changes in the context of the competition conditions, accelerated abilities, and aerobic capacity which can help improve physical fitness.[15] It is a model of capacity referee's development.[16][17] The development of professional football requires the referee's physical fitness to be excellent. Athletic training is one of the motor activities that can affect their physical load.[18] As in Germany, the existence of professional referees is very much needed because the number of referees is decreasing and they consider the refereeing profession to be of no value. The results showed that the respect given by athletes, coaches and spectators to referees can increase their desire to continue their work as referees.[19] In the Covid-19 pandemic era, referee's ability development can use technology device.[20]

The literature study concluded the capacity of football professional referee from an internal and external factor which related to the official, athlete or spectator. The study shows a different concept in increasing the referee's performance using psychological skills training that is taken from the physical fitness level. This study presented the concept of a referee's ability through psychological skills training with physical fitness. While psychological skills training included relaxation, imagery, and relaxation-imagery combination methods. Relaxation denotes activities that are not accompanied by tension. According to Hidayat,[21] imagery training is a mental process that occurs when a person imagines an object, event, or experience of certain movements through multimodality, such as visual, auditory, kinesthetic, and others. While physical fitness did use FIFA's standard. It used the sprint test and interval test. It sees from high and low physical fitness. It is the as newest concept that presented in

Moreover, during the Covid-19 pandemic, various activities were carried out directly. Football matches are held behind closed doors. Of course, it puts a different burden on the referee in making match decisions. They are not exposed to frequent verbal abuse. However, these conditions do not make the referee a professional person. They are still required to have good behaviour, mental and physical fitness.

Therefore, this research is urgent to do because maintaining the quality of professional football referees must be carried out even though the current condition of the Covid-19 pandemic is happening. It can provide an in-depth understanding of referees in West Java about how to maintain psychology and physical training. It is the as newest concept that was presented in this study. Also, the psychological skills training has designed as the situation and environment characteristic in West Java.

This research contributes to the development of football referees through internal aspects. Referees need to have a strong and healthy mentality to be able to improve their achievements or display their performance optimally when leading the match. Referees need to do systematic psychological skill training to have a strong mentality. Therefore, psychological training is an inseparable part of a general sports training program and is included in training planning. Besides, mental responsibility must be aligned with strong physical fitness, because it can build balance as a professional referee. Thus, this study aimed 
to test the provision of treatment through training in psychological skills such as relaxation, imagery, and relaxation-imagery combination methods as seen from high and low levels of physical fitness.

\section{Materials and Methods}

\subsection{Research Design}

The study used quantitative research through a quasi-experiment design. It used a factorial $3 \times 2$ design. It has independent variables (imagery psychological skills training, relaxation, and imagery-relaxation combination), attribute variables (high and low physical fitness), to the dependent variable (referee performance in leading football matches in West Java). The study was conducted from January - December 2020. So, the study examines the effect of cause and effect that occurs between two independent variables on the dependent variable.[22] It can explain in the below table.

Table 1. Factorial Design $3 \times 2$ in

\begin{tabular}{cccc}
\hline & \multicolumn{3}{c}{ Psychological Skills Training } \\
\cline { 2 - 4 } $\begin{array}{c}\text { Physical } \\
\text { Fitness }\end{array}$ & Imagery(A1) & $\begin{array}{c}\text { Relaxation } \\
\text { (A2) }\end{array}$ & $\begin{array}{c}\text { Imagery- } \\
\text { Relaxation } \\
(\mathrm{A} 3)\end{array}$ \\
\cline { 2 - 4 } High (B1) & A1B2 & A2B1 & A3B1 \\
Low (B2) & A1B2 & A2B2 & A3B2 \\
\hline
\end{tabular}

\subsection{Research Sample}

The research sample consisted of 48 people who were taken by the purposive sampling technique. It shows the differences from convenience sampling, which is determined according to the information that has been previously obtained.[23] The sample as the research subject is a referee who has a provincial level referee license (Code C2) and has led a provincial level competition. The sample was divided into three groups, namely 1) group $\mathrm{A}$ who received psychological relaxation-imagery skill training treatment, 2) group B who received relaxation psychological skill training treatment, and 3) group $\mathrm{C}$ who received imagery psychological skill training treatment. Each group numbered 16 people.

\subsection{Process of Collecting Data}

The study has several ways to collect the data, namely;

a) Pre-test. It is carried out before the treatment is given, namely an assessment of the performance of the referee while leading a football match and given a personal fitness test to measure the referee's Physical Fitness level is high or low. b) Treatment. It is carried out by applying the psychological skills training method in the form of relaxation, imagery, and relaxation-imagery exercises. This treatment is done 3 times a week on West Java for $\mathrm{C} 2 \mathrm{License}$ football referee. It was given 21 times.

c) The post-test. It was carried out after the psychological skills training method program was completed. The sample was assessed again on its performance while leading a football match. Furthermore, the data were analyzed to test the hypothesis.

\subsection{Material of Research}

The instruments of study are as follows;

a) Physical fitness. It is measured using the FIFA Fitness Test for Referee. The test is a standard test used by football referees around the world. The FIFA Fitness Test for Referee consists of two test components, namely the Sprint test and the Interval test. Here is the model of physical fitness;

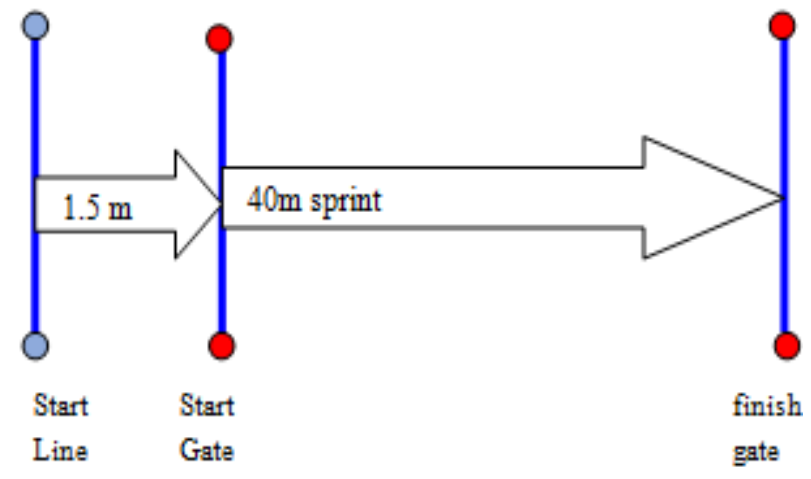

Picture 1. Sprint Test

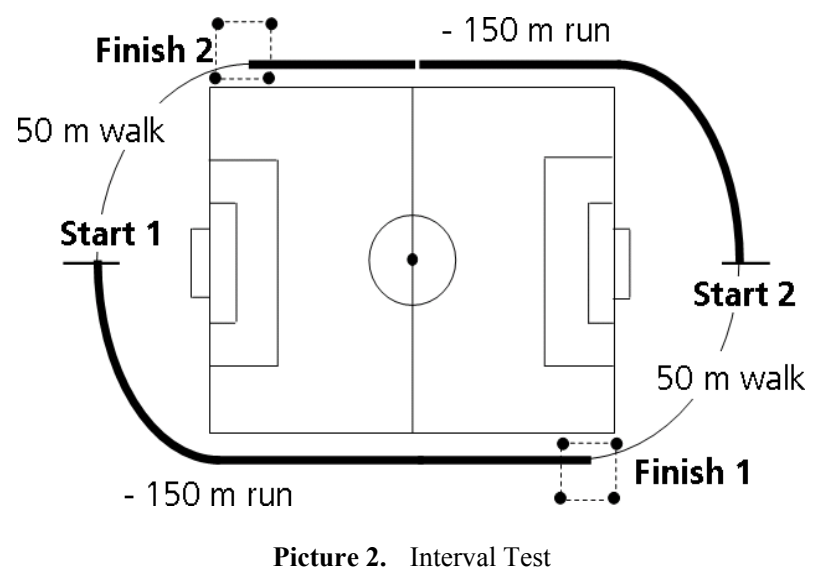

b) Performance Instrument

Performance is measured using an assessment model that is taken from FIFA's assessment standards and is often used by the Indonesian Football Association. The score range is from 4-10. The performance appraisal process is carried out when the referee leads the match for $2 \times 45$ minutes. Here is the component of the referee's 
performance assessment;

Table 2. Performance Dimensions

\begin{tabular}{|c|c|c|}
\hline Dimensions & & Indicators \\
\hline $\begin{array}{l}\text { Official position and } \\
\text { mechanism }\end{array}$ & $\begin{array}{l}\text { b) } \\
\text { c) }\end{array}$ & $\begin{array}{l}\text { Ideal position Goal kicks, corner } \\
\text { kicks and free kicks. } \\
\text { movement } \\
\text { Cooperation and professionalism in } \\
\text { information with assistant referees. }\end{array}$ \\
\hline Game controls & $\begin{array}{l}\text { a) } \\
\text { b) } \\
\text { c) } \\
\text { d) }\end{array}$ & $\begin{array}{l}\text { Frequently Stopping Game } \\
\text { Decision-making } \\
\text { Active in Decision Making } \\
\text { Advantage }\end{array}$ \\
\hline Referee Signal & $\begin{array}{l}\text { a) } \\
\text { b) }\end{array}$ & $\begin{array}{l}\text { Whistle sound } \\
\text { Referee signal }\end{array}$ \\
\hline $\begin{array}{l}\text { Courage, Character, } \\
\text { and Concentration }\end{array}$ & $\begin{array}{l}\text { a) } \\
\text { b) }\end{array}$ & $\begin{array}{l}\text { The calmness of Decision Making } \\
\text { Be Firm in Decision Making }\end{array}$ \\
\hline $\begin{array}{c}\text { Accuracy of } \\
\text { Decision Making }\end{array}$ & $\begin{array}{l}\text { a) } \\
\text { b) } \\
\text { c) }\end{array}$ & $\begin{array}{l}\text { Decision-Making Accuracy } \\
\text { Be clear in making decisions } \\
\text { Right in Making Decisions }\end{array}$ \\
\hline
\end{tabular}

\subsection{Data Analysis}

The process of data analysis has several steps. The data that have been obtained must be normal and homogeneous so that the normality test used the Liliefors test and the homogeneity test used Bartlet. Then, the data were analyzed using a two-way ANOVA. If there is an interaction between the independent variable and the dependent variable, the significant test is continued using the Tuckey test.

\section{Result}

\subsection{The Influence of the Relaxation-Imagery Training on The Referee Performance in Leading Football Match}

The data concluded that relaxation-imagery training has a significant influence on the referee's performance during they led the match. The effect of the Relaxation-Imagery psychological skill training shows that the value of Sig. (2-tailed) $=0.001$, then sig (2-tailed) $<0.05$, thus Ho is rejected and $\mathrm{H} 1$ is accepted. So, it can be concluded that there is an effect of the application of the Relaxation-Imagery Psychological Skills Training method on the performance of West Java referees in leading football.

\subsection{The Influence of The Relaxation Training on the Referee Performance in Leading Football Match}

Relaxation is a technique in behavioural therapy to reduce tension and anxiety. This concept helps the referee gain self-control when there is tension. The effect of psychological relaxation skills training shows that the Sig. (2-tailed) $=0.047$, then sig (2-tailed) $<0.05$, thus Ho is rejected and $\mathrm{H} 1$ is accepted. So, it can be concluded that there is an influence of the Psychological Relaxation skill training method on the performance of West Java referees in leading football.

\subsection{The Influence of the Imagery Training on the Referee Performance in Leading Football Match}

Imagery is a technique commonly used by sports psychologists to help someone visualize or train mentally related to the activities to be carried out, it is given the freedom to imagine using his mind to see and to understand all the possibilities that can occur during a match. The effect of psychological imagery skills training shows that the Sig. (2-tailed) $=0.001$, then sig (2-tailed) $<0.05$, thus Ho is rejected and H1 is accepted. So, it can be concluded that there is an influence of the Psychological Imagery skill training method on the performance of West Java referees in leading football.

\subsection{Interaction Between Psychological Skills Training and Physical Fitness on Referee Performance in Leading Football}

Table 3. The Result of Interaction Between Psychological Skills Training and Physical Fitness

\begin{tabular}{ccc|c|c|c|}
\hline \multicolumn{5}{c}{$\begin{array}{c}\text { Dependent Variable: } \\
\text { Type III Sum }\end{array}$} & \multicolumn{4}{c}{ Referee Performance } \\
Source & $\begin{array}{c}\text { Mean } \\
\text { of Squares }\end{array}$ & df & Square & F & Sig. \\
\hline Corrected Model & $5.542^{\text {a }}$ & 5 & 1.108 & 2.466 & .048 \\
\hline Intercept & 2380.083 & 1 & 2380.083 & 5296.079 & .000 \\
\hline Training & 5.292 & 2 & 2.646 & 5.887 & .006 \\
\hline PF & .083 & 1 & .083 & .185 & .009 \\
\hline Training * PF & .167 & 2 & .083 & .185 & .031 \\
\hline Error & 18.875 & 42 & .449 & & \\
\hline Total & 2404.500 & 48 & & & \\
\hline Corrected Total & 24.417 & 47 & & & \\
\hline
\end{tabular}

a. R Squared $=.227($ Adjusted R Squared $=.135)$

*PF $=$ Physical Fitness

As a result of data analysis, the interaction between psychological skills training and physical fitness helps the referee to build their performance in leading football matches. The interaction between psychological skills training and physical fitness is known that the Sig. $(2$-tailed $)=0.031$, then sig $(2$-tailed) $<0.05$, thus Ho is rejected and $\mathrm{H} 1$ is accepted. So, it can be concluded that there is an interaction between the application of the Psychological Skills Training method and Physical Fitness to the performance of West Java referees in leading football.

The results of the interaction data between 
psychological skills training and physical fitness have implications for the implementation of research for the treatment of groups with high and low physical fitness. Each type of psychological skills training was implemented in a different group of physical fitness.

\subsection{The Effect of Relaxation-Imagery Training Methods on The Referee Performance in Groups with High Physical Fitness}

The result of data showed that relaxation-imagery training has a different influence on performance referee for a high physical fitness group. The effect of relaxation-imagery psychological skills training is known that the value of Sig. (2-tailed) $=0.027$, then sig (2-tailed) $<0.05$, thus Ho is rejected and $\mathrm{H} 1$ is accepted. So, it can be concluded that there is an effect of the application of the Relaxation-Imagery Psychological skill training method on the performance of West Java referees in leading football to referees who have high physical fitness.

\subsection{The Effect of Relaxation-Imagery Training Methods on the Referee Performance in Groups with Low Physical Fitness}

The low physical fitness has different performance in leading the football match. The effect of relaxation-imagery psychological skills training for the group of low physical fitness is known that the value of Sig. (2-tailed) $=0.005$, then sig (2-tailed) $<0.05$, thus Ho is rejected and $\mathrm{H} 1$ is accepted. So, it can be concluded that there is an effect of the application of the Relaxation-Imagery Psychological skill training method on the performance of West Java referees in leading football to referees who have low physical fitness

\subsection{The Effect of Relaxation Training Methods on the Referee Performance in Groups with High Physical Fitness}

It is the result of the data analysis for a group with high physical fitness that has given relaxation training method. The effect of relaxation psychological skills training for the group of high physical fitness is known that the value of Sig. (2-tailed) $=0.046$, then sig $(2$-tailed $)<0.05$, thus Ho is rejected and H1 is accepted. So, it can be concluded that there is an effect of the application of the Relaxation Psychological skill training method on the performance of West Java referees in leading football to referees who have high physical fitness.

\subsection{The Effect of Relaxation Training Methods on the Referee Performance in Groups with Low Physical Fitness}

It is the result of the data analysis for a group with low physical fitness that has given relaxation training method. The effect of relaxation psychological skills training for the group of low physical fitness is known that the value of Sig. (2-tailed) $=0.033$, then sig $(2$-tailed $)<0.05$, thus Ho is rejected and $\mathrm{H} 1$ is accepted. So, it can be concluded that there is an effect of the application of the Relaxation Psychological skill training method on the performance of West Java referees in leading football to referees who have low physical fitness.

\subsection{The Effect of Imagery Training Methods on the Referee Performance in Groups with High Physical Fitness}

It is the result of the data analysis for a group with high physical fitness that has given imagery training method. The effect of imagery psychological skills training for the group of high physical fitness is known that the value of Sig. (2-tailed) $=0.027$, then sig (2-tailed) $<0.05$, thus Ho is rejected and $\mathrm{H} 1$ is accepted. So, it can be concluded that there is an effect of the application of the Imagery Psychological skill training method on the performance of West Java referees in leading football to referees who have high physical fitness.

\subsection{The Effect of Imagery Training Methods on the Referee Performance in Groups with Low Physical Fitness}

It is the result of the data analysis for a group with low physical fitness that has given imagery training method. The effect of imagery psychological skills training for the group of low physical fitness is known that the value of Sig. (2-tailed) $=0.040$, then sig $(2$-tailed $)<0.05$, thus Ho is rejected and $\mathrm{H} 1$ is accepted. So, it can be concluded that there is an effect of the application of the Imagery Psychological skill training method on the performance of West Java referees in leading football to referees who have low physical fitness.

\section{Discussion}

The findings data show that the training of psychological skills and physical fitness has a significant influence on the performance of the referee in the game of football. Al-Haliq, et.al stated that maintained physical fitness can improve performance.[24] It means that psychological condition and physiological markers influenced the referee emotional.[25] Overall, the data show that various types of psychological skill training such as relaxation-imagery, relaxation training, and imagery training also have a major influence on the performance of referees during managing football matches. For referees who have high physical fitness, it is very suitable to practice relaxation-imagery psychological skills and relaxation training. Meanwhile, referees who 
have a low level of physical fitness are more suitable to exercise imagery psychology skills.

The study shows different findings from the psychological skills training activities that have been given to football referees in West Java. Their performance has increased with a stable level of referee emotional control. The different finding appeared in the referee group who had a low level of physical fitness, they still had a good emotional level and control in leading the match. The referees remain calm to receive protests from the players or team officials. So, in good physical condition, either in a high or low condition, if you have psychological stability, you are still able to face various situations that occur during the match. Sports achievement does not only depend on the technical skills of sports and physical health that a person has but also depends on his psychological state and mental health.

In contrast to other studies which conclude that physical condition is a very important part of the training program in maintaining the performance of referees.[26] This means that the energy released by the referee during the match has a considerable influence on the results of the referee's work in leading the match. However, the referee's physical fitness condition may also differ depending on his age and professional level while leading the match.[6] In Turkey, a model of referee performance in making decisions has been adopted from Andrew, et al., that referees must pay attention to accuracy in determining decisions from the aspects of opinion, concentration, self-control and crowd factors that react to players or spectators.[7] The crowd factor has a positive influence on the performance of the referee.[25][26] As has been proven that during the 2019/2020 league season which was carried out behind closed, it was shown that the number of yellow cards issued by the referee was less.[27]

The same study showed that the social pressure factor which comes from the audience or the players gives a difference in the results of the referee's performance in West Java. The treatment given from January to March 2020 has shown quite different results from the treatment given in August to September 2020. During the Covid-19 pandemic, several leagues were conducted behind closed doors and referees had a very stable level of emotional control. This is different from the conditions in January to March 2020, the referee was still affected by the pressure from the audience. However, different things emerged in the group with a high level of physical fitness that was not significantly affected by the referee's decision to lead the match. It means that social pressure from the audience for referees who have a high level of fitness, whether they have received relaxation, imagery or combination psychological skills training, are still able to control emotions and self-control in making decisions.

\section{Conclusions}

The results of this study can be stated that the provision of any psychological skills training program is still directly related to the level of physical fitness. The limitations in this study for the level of measurement of physical fitness are only seen from the aspect of the type of physical exercise that has been used according to FIFA standards. Therefore, this research can still be developed on aspects of physical improvement programs such as providing referees nutrition, and [28] condition of physic.[26] Nutritional intake and good physical condition can meet the energetic demands of leading the competition.[29]

\section{Acknowledgements}

Thanks to all the participants (referees in West Java) who were involved during this research process, the players and team officials involved in the football match to measure the performance of the referee.

\section{REFERENCES}

[1] T. E. Andersen, L. Engebretsen, and R. Bahr, "Rule Violations as a Cause of Injuries in Male Norwegian Professional Football: Are the Referees Doing Their Job?," Am. J. Sports Med., vol. 32, no. SUPPL. 1, Jan. 2004.

[2] C. W. Fuller, A. Junge, and J. Dvorak, "An Assessment of Football Referees' Decisions in Incidents Leading to Player Injuries," Am. J. Sports Med., vol. 32, no. SUPPL. 1, pp. 1722, Jan. 2004.

[3] T. Dohmen and J. Sauermann, "REFEREE BIAS," J. Econ. Surv., vol. 30, no. 4, pp. 679-695, Sep. 2016.

[4] M. Raab, S. Avugos, M. Bar-Eli, and C. MacMahon, "The referee's challenge: a threshold process model for decision making in sport games," Int. Rev. Sport Exerc. Psychol., pp. $1-21,2020$.

[5] S. Boyer, C. MacMahon, M. Récopé, and G. Rix-Lièvre, "The assistant referees' activity in refereeing elite football: Preoccupations when not judging offside," Psychol. Sport Exerc., vol. 48, May 2020.

[6] C. Castagna, G. Abt, and S. D’Ottavio, "Physiological aspects of soccer refereeing performance and training," Sports Medicine, vol. 37, no. 7. Sports Med, pp. 625-646, 2007.

[7] Y. Can, M. Bayansalduz, F. Soyer, and S. Pacali, "Turkish Adaptation of Soccer Referee Decision Satisfaction Scale (SRDSS)," Procedia - Soc. Behav. Sci., vol. 152, pp. 756760, Oct. 2014.

[8] A. M. Nevill, N. J. Balmer, and A. Mark Williams, "The influence of crowd noise and experience upon refereeing decisions in football," Psychol. Sport Exerc., vol. 3, no. 4, pp. 261-272, Oct. 2002.

[9] T. Webb, M. Dicks, R. Thelwell, J. van der Kamp, and G. 
Rix-Lievre, "An analysis of soccer referee experiences in France and the Netherlands: Abuse, conflict, and level of support," Sport Manag. Rev., vol. 23, no. 1, pp. 52-65, Feb. 2020.

[10] B. L. Jacobs, J. K. Tingle, B. D. Oja, and M. A. Smith, "Exploring referee abuse through the lens of the collegiate rugby coach," Sport Manag. Rev., vol. 23, no. 1, pp. 39-51, Feb. 2020.

[11] A. M. Hassan, A. H. Ali, and H. N. H. Alshawi, "The relationship of refereeing performance of the leading personality and thyroxin hormone level for football referees (First division)," Indian J. Forensic Med. Toxicol., vol. 14, no. 2, pp. 875-878, Apr. 2020.

[12] Komarudin, Psikologi Olahraga. Bandung: PT Remaja Rosdakarya, 2013

[13] N. Orviz-Martínez, M. Botey-Fullat, and S. Arce-García, "Analysis of burnout and psychosocial factors in grassroot football referees," Int. J. Environ. Res. Public Health, vol. 18, no. 3, pp. 1-18, Feb. 2021

[14] J. Aragão e Pina, A. M. Passos, M. T. Maynard, and J. Sinval, "Self-efficacy, mental models and team adaptation: A first approach on football and futsal refereeing," Psychol. Sport Exerc., vol. 52, p. 101787, Jan. 2021

[15] D. Castillo, J. Yanci, J. A. Casajús, and J. Cámara, "Physical fitness and physiological characteristics of soccer referees," Sci. Sport., vol. 31, no. 1, pp. 27-35, Feb. 2016.

[16] T. Webb, J. O'Gorman, and L. Markham, "Striving for excellence: talent identification and development in English football refereeing," Eur. Sport Manag. Q., 2020.

[17] M. Weston, C. Castagna, F. M. Impellizzeri, M. Bizzini, A. M. Williams, and W. Gregson, "Science and medicine applied to soccer refereeing: An update," Sports Medicine, vol. 42, no. 7. pp. 615-631, 2012.

[18] K. Ai, R. Oldrich, H. Tan, and P. Xu, "Sustainable innovation in football referee training in Czech Republic," Sustain., vol. 12, no. 7, Apr. 2020.

[19] T. Giel and C. Breuer, "The determinants of the intention to continue voluntary football refereeing," Sport Manag. Rev., vol. 23, no. 2, pp. 242-255, Apr. 2020.
[20] U. Gulec, M. Yilmaz, V. Isler, R. V. O’Connor, and P. M. Clarke, "A 3D virtual environment for training soccer referees," Comput. Stand. Interfaces, vol. 64, pp. 1-10, May 2019.

[21] Y. Hidayat, Psikologi Olahraga. Bandung: FPOK.UPI, 2011.

[22] M. J. C. Crump, D. Navarro, and J. Suzuki, Answering Questions with Data (Textbook): Introductory Statistics for Psychology Students. Online Textbook: https://crumplab.git hub.io/statistics/, 2018.

[23] J. R. Frenkle, How to Design and Evaluate Research in Education. San Francisco: San Francisco State University, 2012 .

[24] M. AL-Haliq, E. Abu-Shihab, M. Al-Kloub, and I Harafsheh, "Testing the Level of Knowledge of Physical Fitness among the Employees of Hashemite University," Int. J. Hum. Mov. Sport. Sci., vol. 9, no. 1, pp. 156-162, Jan. 2021. DOI: $10.13189 /$ saj.2021.090122.

[25] F. L. Naji, T. F. T. Kamalden, and S. Amri, "Psychological distress and physiological markers: Differences comparison in first division football players," Int. J. Hum. Mov. Sport. Sci., vol. 8, no. 1, pp. 43-49, 2020. DOI: 10.13189/saj.2020.080106.

[26] L. Gianturco et al., "Foot and soccer referees': A pilot study searching 'Performance' throughout prevention," Front. Physiol., vol. 9, no. JUL, Jul. 2018.

[27] A. Bryson, P. Dolton, J. J. Reade, D. Schreyer, and C. Singleton, "Causal effects of an absent crowd on performances and refereeing decisions during Covid-19," Econ. Lett., vol. 198, p. 109664, Jan. 2021.

[28] R. Regnoli, M. Rovelli, V. Gianturco, F. E. Pregliasco, B. D. Bodini, and L. Gianturco, "Individualized breakfast programs or glycogen super-compensation: Which is the better performing strategy? insights from an Italian soccer referees cohort," Int. J. Environ. Res. Public Health, vol. 17, no. 3, Feb. 2020.

[29] A. I. Da Silva, L. C. Fernandes, and R. Fernandez, "Energy expenditure and intensity of physical activity in soccer referees during match-play," J. Sport. Sci. Med., vol. 7, no. 3, pp. 327-334, Sep. 2008. 